University of Nebraska - Lincoln

DigitalCommons@University of Nebraska - Lincoln

\title{
The Relation Between the Arterial Stress and Restenosis Rate After Coronary Stenting
}

\author{
Linxia Gu \\ University of Nebraska-Lincoln, gul@fit.edu \\ Shijia Zhao \\ University of Nebraska-Lincoln \\ Aswini K. Muttyam \\ C-Lock Technology Inc., Rapid City, SD \\ James M. Hammel \\ University of Nebraska Medical Center
}

Follow this and additional works at: https://digitalcommons.unl.edu/mechengfacpub

Part of the Mechanical Engineering Commons

Gu, Linxia; Zhao, Shijia; Muttyam, Aswini K.; and Hammel, James M., "The Relation Between the Arterial Stress and Restenosis Rate After Coronary Stenting" (2010). Mechanical \& Materials Engineering Faculty Publications. 41.

https://digitalcommons.unl.edu/mechengfacpub/41

This Article is brought to you for free and open access by the Mechanical \& Materials Engineering, Department of at DigitalCommons@University of Nebraska - Lincoln. It has been accepted for inclusion in Mechanical \& Materials Engineering Faculty Publications by an authorized administrator of DigitalCommons@University of Nebraska Lincoln. 


\author{
Linxia Gu ${ }^{1}$ \\ e-mail: Igu2@unl.edu \\ Shijia Zhao \\ Department of Mechanical Engineering, \\ University of Nebraska-Lincoln, \\ Lincoln, NE 68588-0656 \\ Aswini K. Muttyam \\ C-Lock Technology Inc., \\ Rapid City, SD 57701

\section{James M. Hammel} \\ Department of Surgery, \\ University of Nebraska Medical Center, \\ Omaha, NE 68114
}

\section{The Relation Between the Arterial Stress and Restenosis Rate After Coronary Stenting}

Two commercially available stents (the Palmaz-Schatz (PS) and S670 stents) with reported high and low restenosis rates, respectively, have been investigated in this paper. Finite element models simulating the stent, plaque, and artery interactions in $3 \mathrm{~mm}$ stenosed right coronary arteries were developed. These models were used to determine the stress field in artery walls after stent implantation. The material properties of porcine arteries were measured and implemented in the numerical models. The stress concentration induced in the artery by the PS stent was found to be more than double that of the $S 670$ stent. It demonstrated a good correlation with the reported restenosis rate. The effects of stent structures, compliance mismatch, plaque geometry, and level of stenosis were studied. Results suggested that stent designs and tissue properties cause alterations in vascular anatomy that adversely affect arterial stress distributions within the wall, which impact vessel responses such as restenosis. Appropriate modeling of stent, plaque, and artery interactions provided insights for evaluating alterations to the arterial mechanical environment, as well as biomechanical factors leading to restenosis. [DOI: $10.1115 / 1.4002238$ ]

Keywords: restenosis, stent, plaque, artery, interface, correlation, finite element method

\section{Introduction}

In the United States, 1.2 million patients undergo stent implantations each year. Unfortunately, nearly one-third of the patients who receive stent implantation require further intervention within 6 months to reopen previously stented arteries [1,2]. The major issue associated with stenting is in-stent restenosis (reclosure or renarrowing of the transverse section of the artery) $[3,4]$.

Enormous efforts have been made to identify the predictors of restenosis. Numerous clinical studies have looked into the biological causes and remedies of restenosis, including tissue injury and response [5-9]. Smooth muscle cell production, endothelial cell abundance, and fibroblast growth factors are all believed to lead to restenosis. Clinical trials with and without drug-eluting coatings have reported restenosis rates more associated with stent design [10-12]. The in vivo experiments by Wentzel et al. demonstrated the increased vascular wall stress immediately after balloon angioplasty [13]. Gourisankaran and Sharma found significant stress gradients, stress concentrations, and bending at the junction of the intimal wall and plaque after balloon angioplasty [14]. These observations are extended to this work. Palmaz [15] observed that cell proliferation starts around stent struts and extends eccentrically toward the lumen. It is speculated that the changes in local stress at the diseased area initiate cell proliferation until the stress value returns to normal in the vessel after a period of approximately 8 weeks. However, all these observations need to be validated using experimental and/or numerical approaches.

Finite element methods provide an excellent means to investigate the mechanical implications associated with vascular stenting. Computational studies on stent-tissue interaction have been reported [16-19]. De Beule et al. investigated the dogbone effect of stent implantation [20] and summarized the computational stent modeling from 1997 to 2007 [21]. Berry et al. used finite element methods to examine the stresses in the artery wall near the ends of the stent [22]. Bedoya et al. studied the length of the connecting

${ }^{1}$ Corresponding author.

Manuscript received May 19, 2010; final manuscript received July 16, 2010; published online August 31, 2010. Assoc. Editor: Paul A. Iaizzo. links between two struts, known as strut spacing, the radius of the curvature at the ends of links connecting the struts, and the amplitude of the corrugated sinusoid-like rings [23].

In this work, the correlation between stress concentration and the reported restenosis rate $[10,24]$ was investigated through stentplaque-artery interactions. Three-dimensional models simulating stent expansion in a $3 \mathrm{~mm}$ stenosed right coronary artery were developed to determine stress and strain in the artery wall after stent implantation using the finite element software, ABAQUS (Hibbitt, Karlsson \& Sorensen, Inc., RI). The arterial properties obtained from porcine samples were measured and implemented into the computational models. The stress and strain distributions developed in the artery models were compared for two commercial stents with reported high and low restenosis rates [25,26]. The effects of stent properties, compliance mismatch, plaque geometry including its asymmetry, and level of stenosis were investigated.

\section{Material and Method}

A coronary artery segment with a lumen diameter of $3 \mathrm{~mm}$ with $13 \mathrm{~mm}$ long plaques at various stenosis rates is considered in this work (Fig. 1). A stent was placed across the whole plaque and was inflated, by a balloon, to $3 \mathrm{~mm}$ in diameter to restore blood flow.

2.1 Geometry. The balloon-expandable Palmaz-Schatz (PS) stent and S670 stent (Medtronic), as shown in Fig. 2, were modeled using the commercial software SOLIDWORKS (Dassault Systèmes SolidWorks Corp., Concord, MA), which has the capability of creating complex solid and surface models. Then, the models were imported into ABAQUS to perform a nonlinear large deformation analysis. The rationale in choosing these stent types is that they represent two generations of stent design. It is reported that the PS stent has a restenosis rate of $31.6 \%$ and that the S670 stent has a restenosis rate of $16 \%$ from Medtronic PREDICT trail $[25,26]$. Both stents have an outer diameter of $1.2 \mathrm{~mm}$, a length of $16 \mathrm{~mm}$, and a thickness of $0.1 \mathrm{~mm}$ in their crimped states. There are 5 slots in the longitudinal direction and 12 slots circumferentially. However, the strut and connecting link geometries are different. 

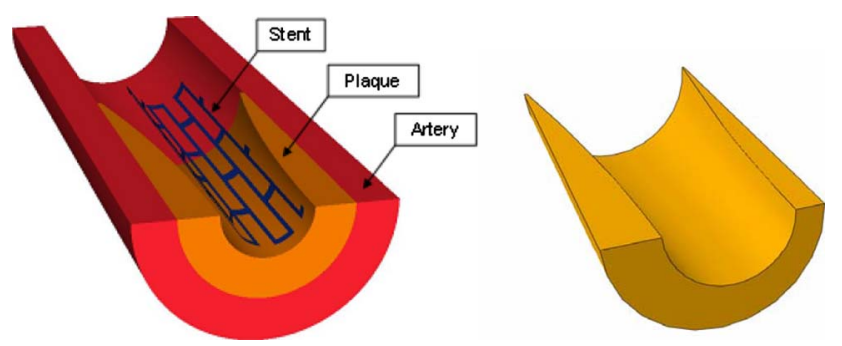

Fig. 1 Solid model of a symmetric stenosed coronary artery segment with PS stent in its constricted form (half model) and an asymmetric plaque with edge ratio of 2:1

The artery was modeled as a perfectly homogeneous cylinder with a length of $26 \mathrm{~mm}$ and a lumen diameter of $3 \mathrm{~mm}$. The thickness of the artery was $0.75 \mathrm{~mm}$ or $1 / 4$ of the lumen thickness. The geometry of the artery was generated by revolving a rectangle (with a width equal to the artery thickness) about the symmetrical axis.

Parabolic longitudinal profiles were used to simulate three symmetrical plaque shapes and one asymmetrical plaque (Fig. 1). The longitudinal lengths of these plaques were the same, i.e., $13 \mathrm{~mm}$. The maximum thickness of the plaque was varied to produce a certain level of stenosis, which is defined as the ratio of the maximum plaque thickness to the size of the lumen. Table 1 summarizes the internal diameter, thickness, and stenosis of symmetrical plaques. The only difference in aymmetrical plaque is that one side is two times thicker than the other side.

2.2 Material Properties. The arteries from a healthy piglet were tested in our laboratory. A second order hyperelastic isotropic constitutive model was used to fit the test data. This model, shown in Fig. 3, is labeled as polynomial model fitting. Its constitutive relation is represented by the following polynomial strain energy density function, $U$, as

$$
\begin{aligned}
U= & C_{10} \cdot\left(I_{1}-3\right)+C_{01} \cdot\left(I_{2}-3\right)+C_{11} \cdot\left(I_{1}-3\right) \cdot\left(I_{2}-3\right) \\
& +C_{20} \cdot\left(I_{1}-3\right)^{2}+C_{02} \cdot\left(I_{2}-3\right)^{2}+C_{03} \cdot\left(I_{2}-3\right)^{3}
\end{aligned}
$$

where $C_{i j}$ are material coefficients determined from the experiments, while $I_{1}$ and $I_{2}$ are the first and second invariants of the Cauchy-Green tensor, respectively.

$I_{1}=\lambda_{1}^{2}+\lambda_{2}^{2}+\lambda_{3}^{2}$, and $I_{2}=1 / \lambda_{1}^{2}+1 / \lambda_{2}^{2}+1 / \lambda_{3}^{2}$. The uniaxial test is characterized in terms of principle stretch $\left(\lambda_{1}, \lambda_{2}, \lambda_{3}\right)$ as $\lambda_{1}=\lambda_{U}$ and $\lambda_{2}=\lambda_{3}=1 / \sqrt{\lambda_{U}}$. Subsequently, $I_{1}=\left(\lambda_{U}^{2}+2\right) / \lambda_{U}$, and $I_{2}=(1$ $\left.+2 \lambda_{U}^{3}\right) / \lambda_{U}$. The nominal stress $\sigma_{U}$ is derived as
Table 1 Description of the plaque geometries and stenosis rate

\begin{tabular}{lcc}
\hline \hline Type & $\begin{array}{c}\text { Maximum thickness } \\
\text { of plaque }(\mathrm{mm})\end{array}$ & $\begin{array}{c}\text { Stenosis rate } \\
\text { at a lumen of } 1.5 \mathrm{~mm} \\
\text { in radius }(\%)\end{array}$ \\
\hline Plaque 1 & 0.6 & 40 \\
Plaque 2 & 0.7 & 47 \\
Plaque 3 & 0.8 & 53 \\
\hline \hline
\end{tabular}

$$
\begin{aligned}
\sigma_{U}= & 2\left(\frac{\lambda_{U}^{3}-1}{\lambda_{U}^{3}}\right)\left[\left(\lambda_{U} C_{10}\right)+\left\{C_{01}+2 C_{02}\left(\frac{1+2 \lambda_{U}^{3}-3 \lambda_{U}^{2}}{\lambda_{U}^{2}}\right)\right.\right. \\
& \left.\left.+3 C_{03}\left(\frac{1+2 \lambda_{U}^{3}-3 \lambda_{U}^{2}}{\lambda_{U}^{2}}\right)^{2}\right\}\right]
\end{aligned}
$$

Based on our test data, the calculated material constants for the artery were $C_{10}=0.10881, C_{01}=-0.1010042, C_{11}=-0.179067494$, $C_{20}=0.0885618$, and $C_{02}=0.062686$. This constitutive model agrees with the published material model very well [16,27-29], as shown in Fig. 3. The material properties of plaque are directly adopted from Auricchio et al. [16], defined by the polynomialexponential strain energy density function as $C_{10}=0.04, C_{02}$ $=0.003$, and $C_{03}=0.02976$. Coefficients of plaque were selected to simulate a calcified plaque, which is stiffer than the arterial wall.

The stents are made of 316LN stainless steel whose material properties are Young's modulus $\mathrm{E}=190 \mathrm{GPa}$, Poisson's ratio $\nu$ $=0.3$, yield stress $\sigma_{\mathrm{Y}}=207 \mathrm{MPa}$, limit stress $\sigma_{\mathrm{M}}=515 \mathrm{MPa}$, and limit nominal strain $\varepsilon_{M}=60 \%$. The plastic behavior of stents was modeled assuming isotropic hardening, which was validated by Auricchio et al. [16].

2.3 Meshing and Boundary Conditions. Both stents were meshed with four-node general shell elements (S4R), which accounts for transverse shear stresses and strains. Considering the incompressibility of soft tissues, hybrid eight-node brick elements $(\mathrm{C} 3 \mathrm{D} 8 \mathrm{H})$ were used to mesh the plaque and artery to avoid locking problems. Convergence studies, as shown in Fig. 4, were conducted to determine an adequate mesh size. The results indicate that a mesh with 15,210 elements in the plaque and 28,644 elements in the artery is reasonable.

Careful observations of in vivo stenting procedures at the $\mathrm{Ne}$ braska Heart Institute and in vitro stent expansion experiments in our laboratory (Fig. 5) have shown that the balloon is almost uniformly inflated. The free ends of the stent are easier to expand than the central portion; thus, the ends of the stent expand faster at the beginning of the expansion so that there is less pressure exerted by the balloon on the stent ends during further expansion.

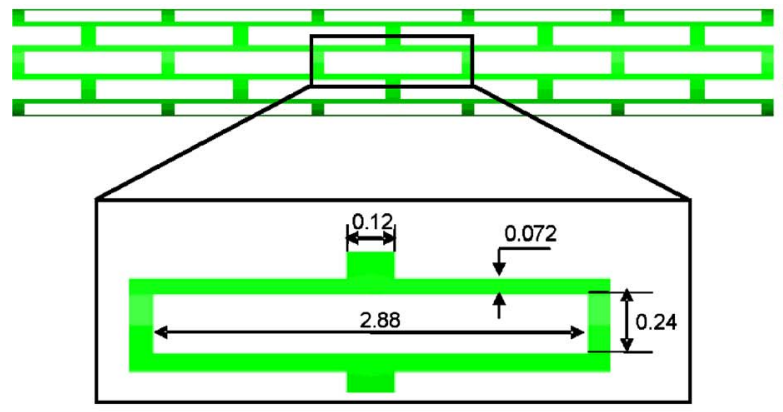

(a)

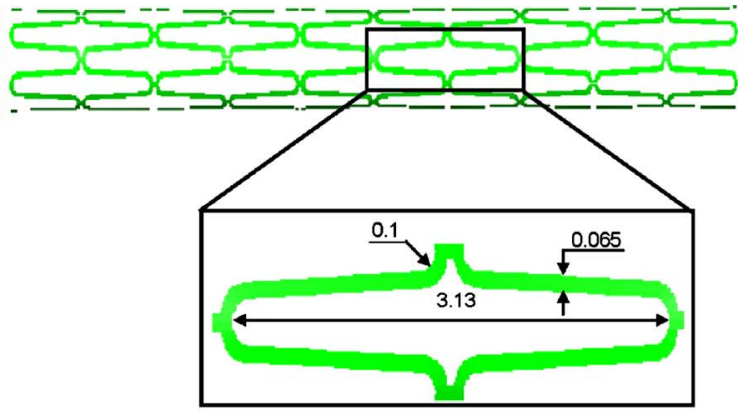

(b)

Fig. 2 Geometry of (a) PS stent and (b) S670 stent 


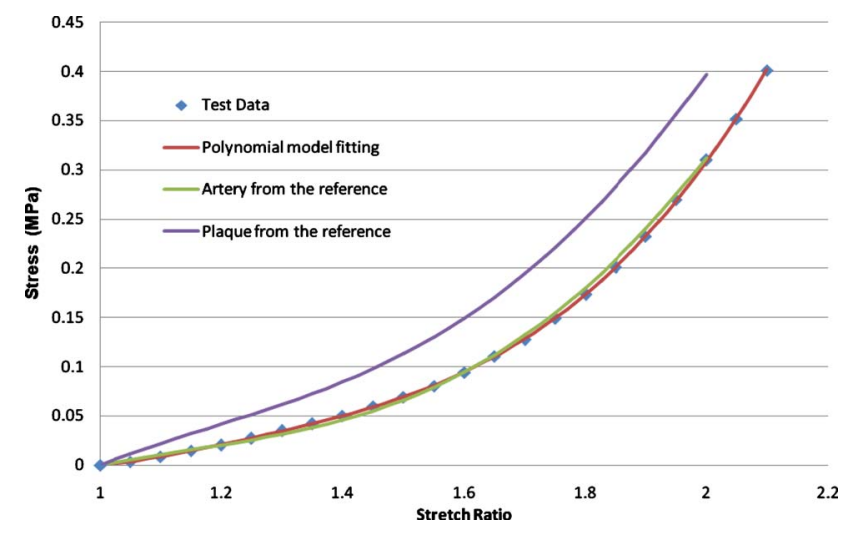

Fig. 3 True stress versus stretch ratio curve for plaque and artery

The central portion of the stent continues to be dilated by the balloon until the stent is almost evenly expanded. Therefore, in this study, uniform displacement constraints were applied to the internal surface of stents until the final diameter of the stent reached $3 \mathrm{~mm}$. The ends of the artery were constrained in the axial direction to avoid the tangential motion and rotation of the model. A finite, sliding surface-to-surface contact between stent, plaque, and artery, without friction, was prescribed. A finite sliding ap-

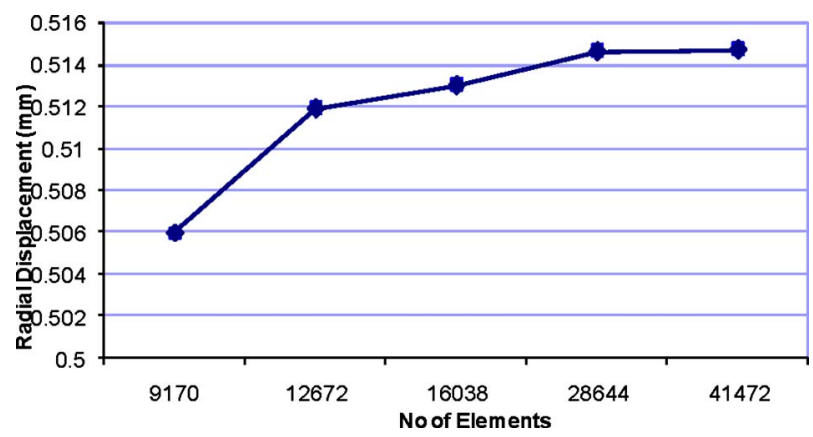

Fig. 4 Maximum radial displacement in the artery wall with five different meshes
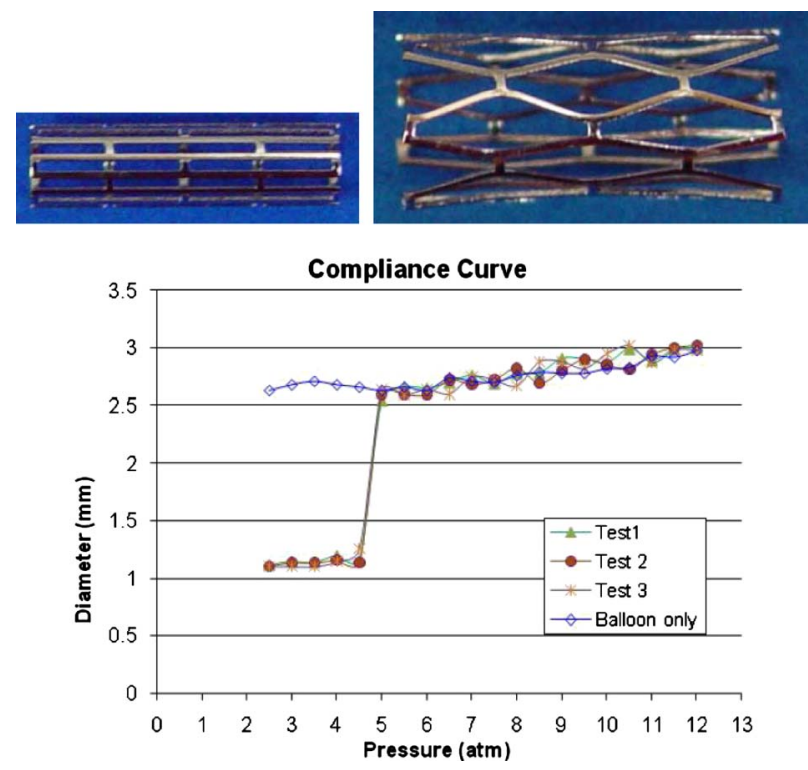

Fig. 5 In vitro expansion of a PS stent from $1.2 \mathrm{~mm}$ to $3 \mathrm{~mm}$ diameter

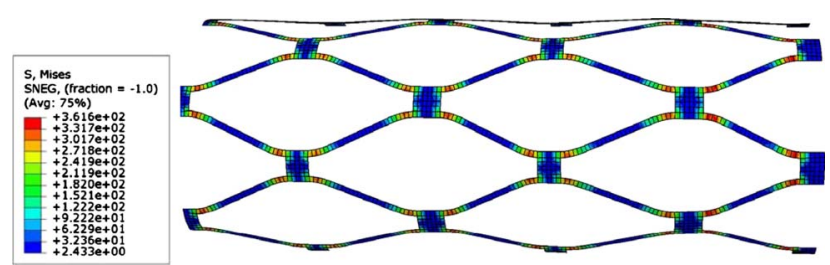

Fig. 6 Expanded PS stent

proach is the most general tracking approach and allows for arbitrary relative separation, sliding, and rotation of the contact surfaces. Three-dimensional models simulating the stent expansion in the stenosed artery were developed to predict the stress and strain field in the artery wall as a result of stent implantations.

\section{Results and Discussions}

Stents were uniformly expanded to more than twice of their initial diameter. The expanded PS stent had a diamond-shaped slot after expanding from the initial outer diameter of $1.2 \mathrm{~mm}$ to 3 $\mathrm{mm}$. The average normal force on the inside of the stent was 3.1 $\mathrm{N}$ at the $3 \mathrm{~mm}$ diameter, which corresponds to an equivalent average pressure of $10.5 \mathrm{~atm}$. This is slightly lower than the tested $11.5 \mathrm{~atm}$ expansion pressure depicted in Fig. 5. This is due to the fact that the compliance data are obtained by measuring the center diameter of the stent only. The simulation, however, is expanded uniformly. This led to a nonuniform pressure with a lower pressure at the end of the stent and a smaller total average equivalent pressure under displacement constraints. This bare stent expansion model, as shown in Fig. 6, demonstrated the stress concentrations around the stent links, as expected, which fit the in vitro expended shape (Fig. 5) very well.

The rates of restenosis after stenting varied significantly depending on the generation of stent. Two generations of commercial stents, the PS and S670 stents, with reported high and low restenosis rates, respectively, were investigated in this work. While both stents were expanded to $3 \mathrm{~mm}$ diameter, the PS stent induced higher stresses over larger areas of the arterial wall than the S670 stent, as demonstrated in Fig. 7. This agrees with the speculations of Bedoya et al. They suggested that stents with large spacing will benefit the host artery by imparting lower magnitude stresses and will, therefore, diminish the risk of injury to the vessel wall [23].

Clinical trials reported that the restenosis rate of the PS stent is almost double that of the S670 stent $[25,26]$. Our computational results showed that the maximum arterial stress caused by the PS stent is double compared to the S670 stent induced arterial stress. There exists a correlation between the restenosis rate and the maximum arterial stress, which supports our hypothesis that stress concentration in the stented vessel wall correlates with the restenosis rate.

The S670 stent also exhibited a smaller compliance mismatch within the artery, as illustrated in Fig. 8. It is clear that the S670 stent, with its larger spacing between struts, provided a smoother compliance transition between the central and end stented regions.

The stress developed in the artery along the stent strut, the path with the highest local stresses, is depicted in Fig. 9. It is interesting to see that the S670 stent induced less stress and stress gradients in the artery wall than the PS stent under the same level of stenosis. The highest arterial stresses occurred at the end of the plaque in both stent simulations. Maximum von Mises stresses in the artery at three typical axial locations are summarized in Table 2 for both stents. The highest stress at the plaque edge was due to the surface contact between the plaque and artery. The plaque and artery were strongly bonded to each other in general. When the stent pushed the plaque outward in the radial direction, the plaque tried to stretch itself and pull the connected artery in the longitudinal direction, as demonstrated in Fig. 9 (zoom-in). This in turn 

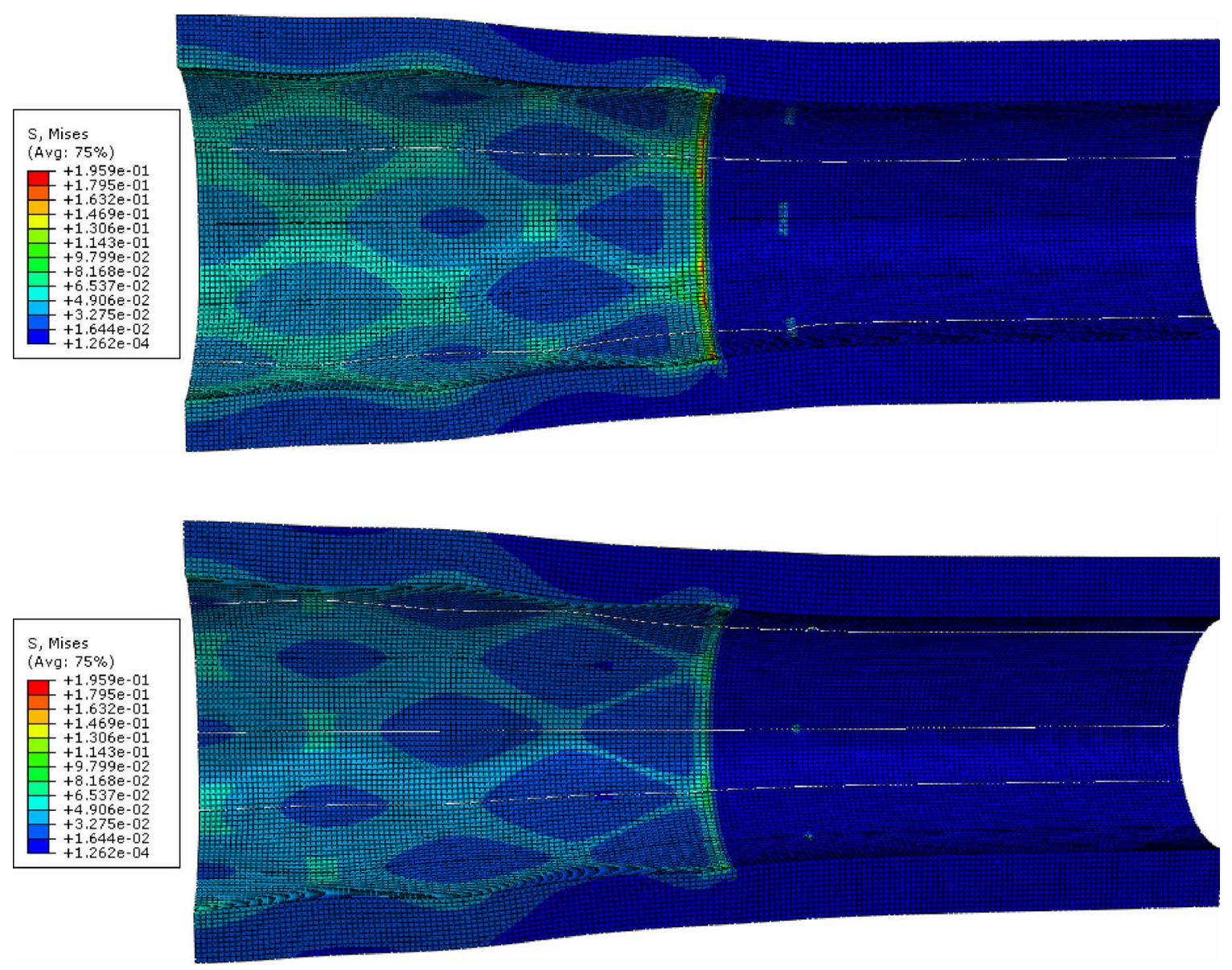

Fig. 7 von Mises stress distribution on the $40 \%$ stenosed artery wall treated with PS stent (top) and S670 stent (bottom)

caused the larger stress and stress gradient at the end of the plaque. Excessive stretching of the artery can trigger massive proliferation of smooth muscle cells, which leads to restenosis of the artery. This indicates that a large strut spacing and a small width are preferred in a stent design to reduce its impact on the arterial wall.

Our results have demonstrated that two different stent designs induce different levels of stress concentration in the artery. Moreover, stress levels in the artery wall are also dependent on other factors such as the level of stenosis. For comparison, various stenosis levels of $40 \%, 47 \%$, and $53 \%$ were simulated. The von Mises stresses in the artery along the same strut path (defined in Fig. 9) are plotted in Fig. 10. It is clear that the severer the stenosis level, the higher the resultant arterial stresses.

To illustrate the effect of the plaque geometries, the thickness at the end of the plaque was modified from $0.1 \mathrm{~mm}$ to $0.037 \mathrm{~mm}$. Subsequently, the stress distribution changed dramatically, as shown in Fig. 11. It is clear that the highest stress is located in the center of the plaque instead of at the plaque edge. The peak stress experienced by the artery is $0.063 \mathrm{MPa}$. The excessive stretching at the end of the plaque is alleviated, which in turn reduced the local peak stresses.

The effects of stent design become more important in asymmetrical plaques, as shown in Fig. 1. We have compared the symmetric and asymmetric plaques with the same $50 \%$ stenosis and have expanded them by the PS stent to the desired $3 \mathrm{~mm}$ native lumen size, as shown in Table 3. The stress almost doubled due to the asymmetry. This change will in turn increase the possibility of restenosis.

\section{Conclusion}

During the course of stent implantation, the stent structure applies much higher mechanical forces than under normal physiological conditions, and it stimulates and even injures the stenosed vessel walls. The arterial response, such as restenosis, will depend on a number of factors including stent design, mechanical properties of artery and plaque, and their geometries [30-34]. The correlation between stent designs and the restenosis rate is not yet clearly understood. In this study, computational models were used to predict the impact of two stent designs and gather a better fundamental understanding of the stent-plaque-artery interactions that govern the stress field within these diseased lesions.

This study's results show that stent design influences the stress and strain field within the artery wall. Even when both stents are expanded to the same final dimensions, the PS stent, which has a small strut spacing and a large strut width, was found to induce $10 \%$ or larger stresses and radial displacements in the artery wall compared to the S670 stent. The maximum stress or strain gradients within the artery are dependent upon the geometry of the plaque. Stent induced arterial stresses increase with the severity of the stenosis leve1. As the thickness of the plaque increased from $0.6 \mathrm{~mm}$ to $0.8 \mathrm{~mm}$, the maximum stress and its gradient on the artery wall varied significantly, more than doubling for both stent models. The plaque asymmetry increases the stress level on the arterial wall dramatically. Results in this work suggest that stent design parameters and tissue properties cause alterations in vascular anatomy that adversely affect arterial stress distributions within the wall, which validated our hypothesis that stress concen- 

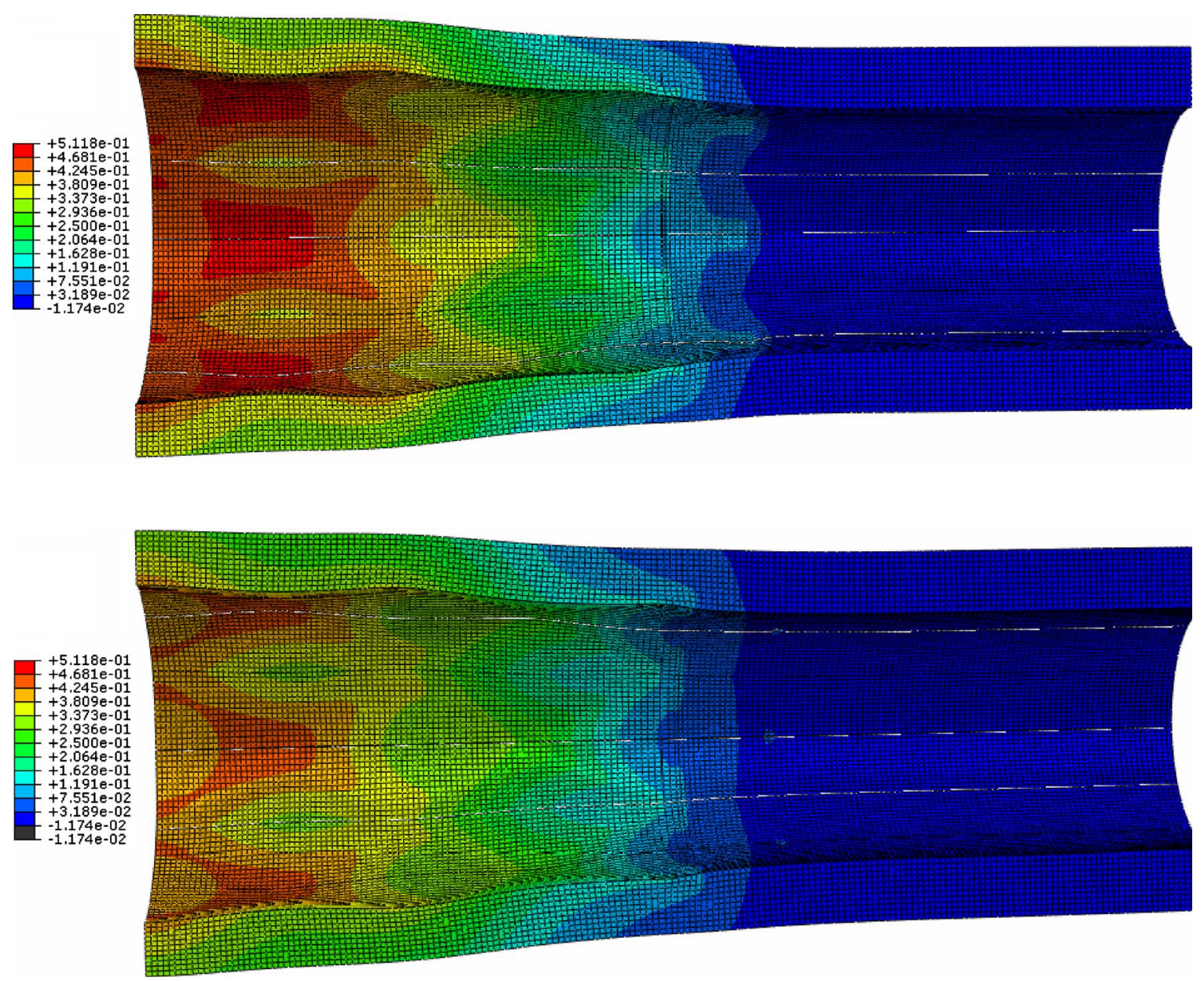

Fig. 8 Radial displacement in the $40 \%$ stenosed artery treated with PS stent (top) and S670 stent (bottom)

tration in the stented vessel wall significantly impacts the restenosis rate. Although the mechanical properties of the artery and plaque varied case by case, the same properties obtained from piglet samples are adopted here for comparisons of the two stent
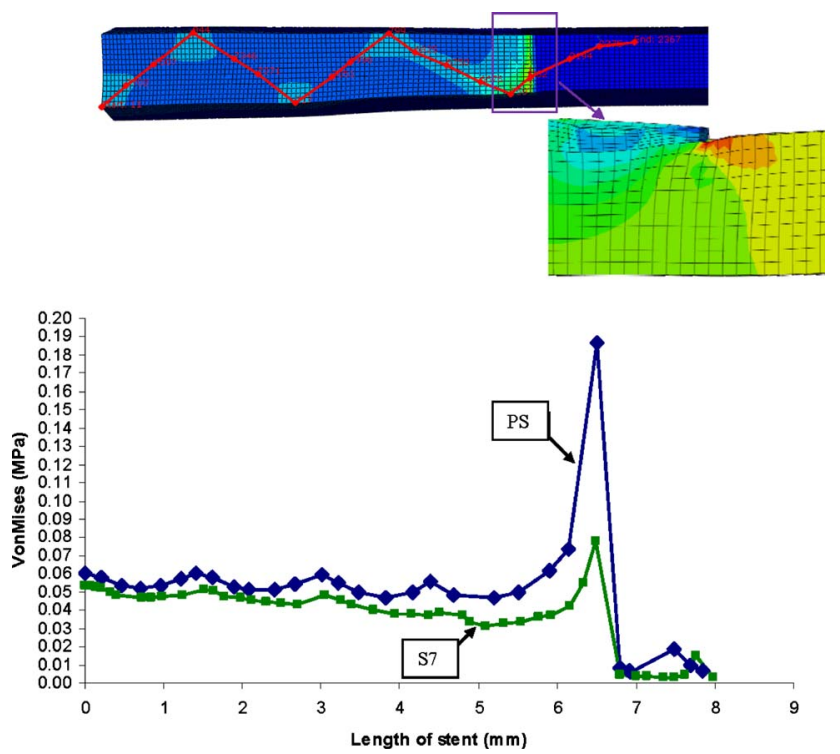

Fig. 9 von Mises stress in the artery along the strut path, and the cross sectional details of the artery-plaque interaction (zoom-in) implantations. The material model was justified due to the comparative nature of this study.

In the present model, a balloon used to inflate the stent was modeled by a controlled displacement. The feasibility of the boundary condition was validated by our in vitro testing. The

Table 2 Local maximum von Mises stress in the $40 \%$ stenosed artery

\begin{tabular}{lccc}
\hline \hline Area & $\begin{array}{c}\text { Plaque center } \\
(\mathrm{MPa})\end{array}$ & $\begin{array}{c}\text { Plaque end } \\
(\mathrm{MPa})\end{array}$ & $\begin{array}{c}\text { Stent end } \\
(\mathrm{MPa})\end{array}$ \\
\hline PS stent & 0.057 & 0.19 & 0.022 \\
S670 stent & 0.051 & 0.09 & 0.019 \\
\hline \hline
\end{tabular}

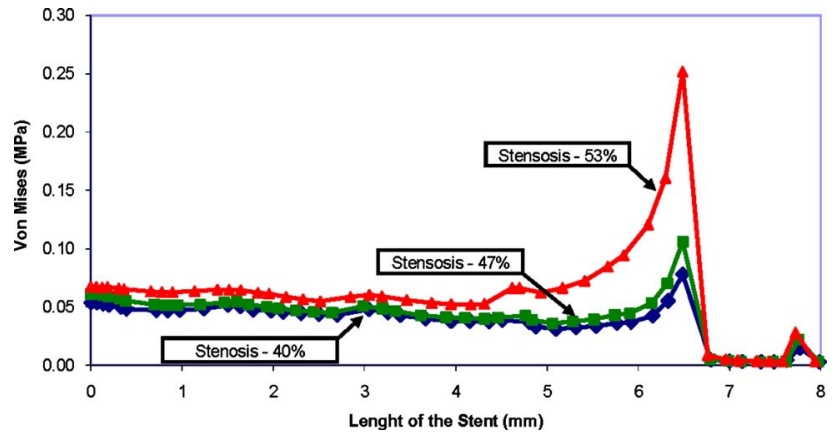

Fig. 10 Arterial stress along the strut path induced by $\mathbf{S 6 7 0}$ stent 

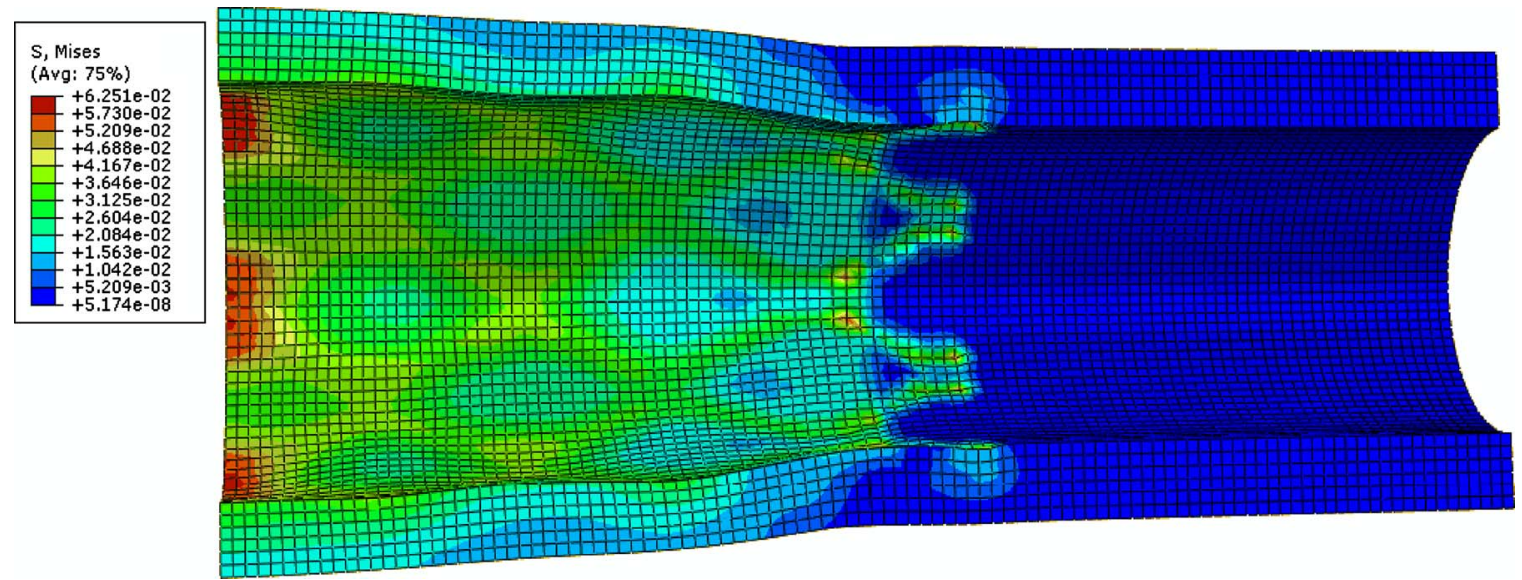

Fig. 11 The von Mises stress distribution in the stented artery ( $40 \%$ stenosis) with a thinner plaque edge

Table 3 The effect of plaque symmetry

\begin{tabular}{lcc}
\hline \hline Plaques & $\begin{array}{c}\text { Maximum von Mises } \\
\text { stress }(\mathrm{MPa})\end{array}$ & $\begin{array}{c}\text { Average local von Mises } \\
\text { stress }(\mathrm{MPa})\end{array}$ \\
\hline Symmetric & 0.0643 & 0.0611 \\
Nonsymmetric & 0.113 & 0.107 \\
\hline \hline
\end{tabular}

porcine artery was tested and the second order polynomial hyperelastic constitutive models were used to represent the plaque and artery. The materials are assumed to be isotropic homogeneous, although the artery and plaque have been shown to be anisotropic and viscoelastic $[29,35]$. The observed stress levels were highest at the end of the plaque due to the high calcification of the plaque in this study. However, the interaction between the stent and the stenosed artery will change, and the peak stress will migrate if a moderate calcification with a larger lipid core is present in the plaque. Advanced material models, as well as hemodynamics effects, are not included in the present model. It should be noted that the stent designs in this study do not completely reflect all the attributes of the wide variety of stents that are presently commercially available. The geometries of the artery and plaque were simplified for this comparative study. More realistic models considering patient specific geometry and nonhomogeneous arterial wall properties will change the stress distribution on the arterial wall. For asymmetric plaque, the pressure boundary control to model the balloon effect will be more appropriate in order to study the underexpansion effect of the stent procedure. Despite these simplifications, the present work demonstrated the importance of stent design in terms of the potential injury to a stenosed vessel, which may have significant clinical implications for in-stent restenosis. This work can be used to provide a fundamental understanding of the behavior and impact of stent designs on the vascular wall, to provide guidance for optimizing stent shape and performance, and to illuminate the possibilities for exploiting their potential to prevent restenosis.

\section{Acknowledgment}

The authors are grateful for the funding from the National Science Foundation under Grant Nos. 0926880 and 0811250.

\section{References}

[1] Lloyd-Jones, D., Rosamond, W., Flegal, K., Friday, G., Furie, K., Go, A., Greenlund, K., Haase, N., Ho, M., Howard, V., Kissela, B., Kittner, S., Mcdermott, M., Meigs, J., Moy, C., Nichol, G., O'Donnell, C. J., Roger, V., Rumsfeld, J., Sorlie, P., Steinberger, J., Thom, T., Wasserthiel-Smoller, S., and Hong, Y., 2009, "Heart Disease and Stroke Statistics-2009 Update: A Report From the American Heart Association Statistics Committee and Stroke Statis- tics Subcommittee," Circulation, 119(5), pp. e1-161.

[2] Hoffmann, R., Mintz, G. S., Dussaillant, G. R., Popma, J. J., Pichard, A. D., Satler, L. F., Kent, K. M., Griffin, J., and Leon, M. B., 1996, "Patterns and Mechanisms of In-Stent Restenosis. A Serial Intravascular Ultrasound Study," Circulation, 94(6), pp. 1247-1254

[3] van der Hoeven, B. L., Pires, N. M. M., Warda, H. M., Oemrawsingh, P. V., van Vlijmen, B. J. M., Quax, P. H. A., Schalij, M. J., van Der Wall, E. E., and Jukema, J. W., 2005, "Drug-Eluting Stents: Results, Promises and Problems," Int. J. Cardiol., 99(1), pp. 9-17.

[4] Anis, R. R., and Karsch, K. R., 2006, "The Future of Drug Eluting Stents," Heart, 92(5), pp. 585-588.

[5] Steinman, D. A., Vorp, D. A., and Ethier, C. R., 2003, "Computational Modeling of Arterial Biomechanics: Insights Into Pathogenesis and Treatment of Vascular Disease," J. Vasc. Surg., 37(5), pp. 1118-1128.

[6] Schwartz, E. A., Bizios, R., Medow, M. S., and Gerritsen, M. E., 1999, "Exposure of Human Vascular Endothelial Cells to Sustained Hydrostatic Pressure Stimulates Proliferation. Involvement of the Alphav Integrins," Circ. Res., 84(3), pp. 315-322.

[7] Becker, G. J., 1991, "Intravascular Stents. General Principles and Status of Lower-Extremity Arterial Applications," Circulation, 83(2), pp. 122-136.

[8] Oesterle, S. N., Whitbourn, R., Fitzgerald, P. J., Yeung, A. C., Stertzer, S. H., Dake, M. D., Yock, P. G., and Virmani, R., 1998, "The Stent Decade: 1987 to 1997. Stanford Stent Summit Faculty," Am. Heart J., 136(4), pp. 578-599.

[9] Hausleiter, J., Kastrati, A., Mehilli, J., Schuhlen, H., Pache, J., Dotzer, F, Dirschinger, J., and Schomig, A., 2002, "Predictive Factors for Early Cardiac Events and Angiographic Restenosis After Coronary Stent Placement in Small Coronary Arteries," J. Am. Coll. Cardiol., 40(5), pp. 882-889.

[10] Kastrati, A., Mehilli, J., Dirschinger, J., Pache, J., Ulm, K., Schuhlen, H. Seyfarth, M., Schmitt, C., Blasini, R., Neumann, F. J., and Schomig, A., 2001, "Restenosis After Coronary Placement of Various Stent Types," Am. J. Cardiol., 87(1), pp. 34-39.

[11] Stone, G. W., and Pocock, S. J., 2010, "Randomized Trials, Statistics, and Clinical Inference,” J. Am. Coll. Cardiol., 55(5), pp. 428-431.

[12] Kirtane, A. J., Gupta, A., Iyengar, S., Moses, J. W., Leon, M. B., Applegate, R., Brodie, B., Hannan, E., Harjai, K., Jensen, L. O., Park, S. J., Perry, R., Racz, M., Saia, F., Tu, J. V., Waksman, R., Lansky, A. J., Mehran, R., and Stone, G. W., 2009, "Safety and Efficacy of Drug-Eluting and Bare Metal Stents: Comprehensive Meta-Analysis of Randomized Trials and Observational Studies," Circulation, 119(25), pp. 3198-3206.

[13] Wentzel, J. J., Kloet, J., Andhyiswara, I., Oomen, J. A., Schuurbiers, J. C., De Smet, B. J., Post, M. J., De Kleijn, D., Pasterkamp, G., Borst, C., Slager, C. J. and Krams, R., 2001, "Shear-Stress and Wall-Stress Regulation of Vascular Remodeling after Balloon Angioplasty: Effect of Matrix Metalloproteinase Inhibition," Circulation, 104(1), pp. 91-96.

[14] Gourisankaran, V., and Sharma, M. G., 2000, "The Finite Element Analysis of Stresses in Atherosclerotic Arteries During Balloon Angioplasty," Crit. Rev. Biomed. Eng., 28(1-2), pp. 47-51.

[15] Palmaz, J. C., 1993, "Intravascular Stents-Tissue-Stent Interactions and Design Considerations," AJR, Am. J. Roentgenol., 160(3), pp. 613-618.

[16] Auricchio, F., Diloreto, M., and Sacco, E., 2001, "Finite Element Analysis of a Stenotic Artery Revascularization Through Stent Insertion," Comput. Methods Biomech. Biomed. Eng., 4, pp. 249-263.

[17] Lally, C., Dolan, F., and Prendergast, P. J., 2005, "Cardiovascular Stent Design and Vessel Stresses: A Finite Element Analysis," J. Biomech., 38(8), pp. $1574-1581$.

[18] Migliavacca, F., Petrini, L., Massarotti, P., Schievano, S., Auricchio, F., and Dubini, G., 2004, "Stainless and Shape Memory Alloy Coronary Stents: A Computational Study on the Interaction With the Vascular Wall," Biomech. Model. Mechanobiol., 2(4), pp. 205-217.

[19] Wu, W., Qi, M., Liu, X. P., Yang, D. Z., and Wang, W. Q., 2007, "Delivery and Release of Nitinol Stent in Carotid Artery and Their Interactions: A Finite 
Element Analysis,” J. Biomech., 40(13), pp. 3034-3040.

[20] De Beule, M., Van Impe, R., Verhegghe, B., Segers, P., and Verdonck, P., 2006, "Finite Element Analysis and Stent Design: Reduction of Dogboning," Technol. Health Care, 14(4-5), pp. 233-241.

[21] De Beule, M., 2009, "Biomechanical Modelling of Stents: Survey 1997 2007," Advances in Biomedical Engineering, Elsevier, Amsterdam, The Netherlands, Chap. 2

[22] Berry, J. L., Manoach, E., Mekkaoui, C., Rolland, P. H., Moore, J. E., Jr., and Rachev, A., 2002, "Hemodynamics and Wall Mechanics of a Compliance Matching Stent: In Vitro and In Vivo Analysis,” J. Vasc. Interv. Radiol., 13(1), pp. 97-105.

[23] Bedoya, J., Meyer, C. A., Timmins, L. H., Moreno, M. R., and Moore, J. E., 2006, "Effects of Stent Design Parameters on Normal Artery Wall Mechanics,' ASME J. Biomech. Eng., 128(5), pp. 757-765.

[24] Younis, G. A., Gupta, K., Mortazavi, A., Strickman, N. E., Krajcer, Z., Perin, E., and Achari, A., 2007, "Predictors of Carotid Stent Restenosis," Catheter. Cardiovasc. Interv., 69(5), pp. 673-682.

[25] Fischman, D. L., Leon, M. B., Baim, D. S., Schatz, R. A., Savage, M. P., Penn, I., Detre, K., Veltri, L., Ricci, D., Nobuyoshi, M., Cleman, M., Heuser, R., Almond, D., Teirstein, P. S., Fish, R. D., Colombo, A, Brinker, J., Moses, J., Shaknovich, A., Hirshfeld, J., Bailey, S., Ellis, S., Rake, R., and Goldberg, S. 1994, “A Randomized Comparison of Coronary-Stent Placement and Balloon Angioplasty in the Treatment of Coronary Artery Disease. Stent Restenosis Study Investigators,” N. Engl. J. Med., 331(8), pp. 496-501.

[26] Baim, D. S., Flatley, M., Caputo, R., O'Shaughnessy, C., Low, R., Fanelli, C., Popma, J., Fitzgerald, P., and Kuntz, R., 2001, "Comparison of PRE-Dilatation Vs Direct Stenting In Coronary Treatment Using the Medtronic AVE S670 Coronary Stent System (the PREDICT Trial)," Am. J. Cardiol., 88(12), pp. 1364-1369.
[27] Petrini, L., Migliavacca, F., Auricchio, F., and Dubini, G., 2004, "Numerical Investigation of the Intravascular Coronary Stent Flexibility," J. Biomech. 37(4), pp. 495-501.

[28] Topoleski, L. D., Salunke, N. V., Humphrey, J. D., and Mergner, W. J., 1997, "Composition- and History-Dependent Radial Compressive Behavior of Human Atherosclerotic Plaque," J. Biomed. Mater. Res., 35(1), pp. 117-127.

[29] Salunke, N. V., Topoleski, L. D., Humphrey, J. D., and Mergner, W. J., 2001, "Compressive Stress-Relaxation of Human Atherosclerotic Plaque," J. Biomed. Mater. Res., 55(2), pp. 236-241.

[30] Glagov, S., 1994, "Intimal Hyperplasia, Vascular Modeling, and the Restenosis Problem," Circulation, 89(6), pp. 2888-2891.

[31] Glagov, S., Bassiouny, H. S., Giddens, D. P., and Zarins, C. K., 1995, "Pathobiology of Plaque Modeling and Complication," Surg. Clin. North Am., 75(4), pp. 545-556.

[32] Glagov, S., Bassiouny, H. S., Sakaguchi, Y., Goudet, C. A., and Vito, R. P., 1997, "Mechanical Determinants of Plaque Modeling, Remodeling and Disruption," Atherosclerosis, 131, pp. S13-S14.

[33] Jacobs, T. S., Won, J., Gravereaux, E. C., Faries, P. L., Morrissey, N., Teodorescu, V. J., Hollier, L. H., and Marin, M. L., 2003, "Mechanical Failure of Prosthetic Human Implants: A 10-Year Experience With Aortic Stent Graft Devices,” J. Vasc. Surg., 37(1), pp. 16-26.

[34] Garcia-Cardena, G., Comander, J., Anderson, K. R., Blackman, B. R., and Gimbrone, M. A., Jr., 2001, "Biomechanical Activation of Vascular Endothelium as a Determinant of Its Functional Phenotype," Proc. Natl. Acad. Sci. 98(8), pp. 4478-4485.

[35] Loree, H. M., Grodzinsky, A. J., Park, S. Y., Gibson, L. J., and Lee, R. T., 1994, "Static Circumferential Tangential Modulus of Human Atherosclerotic Tissue," J. Biomech., 27(2), pp. 195-204. 